case, and it appeared to be so in case 6 also. Buckner et al in Seattle recently reported the results of using cryopreserved autologous bone-marrow cells (supplemented in some cases by peripheral blood leucocytes) in the support of patients with CGL treated for transformation. ${ }^{22}$ They noted that reconstitution of lymphoid cells was defective in some of their patients. If, therefore, blood is a better source of pluripotential stem cells for autografting than bone marrow, ${ }^{2}$ this might be partly because relatively larger numbers of stem cells with lymphoid potential can be collected from the blood than from the marrow.

This approach to the management of CGL can in no sense be regarded as curative. Instead, our preliminary results suggest that it may prolong life in some cases for one or more years.

We thank Dr A W G Goolden, of Hammersmith Hospital, who supervised the administration of the radiotherapy. Valuable technical help was rendered by $M$ Cherchi, D S Park, K H Th'ng, M O'Brien, and S Pittman. We particularly thank members of the medical and nursing staff of the Hammersmith Hospital Anaemia Unit for their care in managing the patients. The agar culture work reported in this paper was supported in part by the Leukaemia Research Fund.

\section{References}

${ }^{1}$ Spiers, A S D, British fournal of Haematology, 1976, 32, 291.

${ }^{2}$ Goldman, J M, et al, British fournal of Haematology, 1978, 40, 185.
3 Graw, R G, jun, et al, Lancet, 1970, 2, 338

${ }^{4}$ Goldman, J M, et al, British fournal of Cancer, 1974, 30, 1.

5 Lowenthal, R M, et al, Leucocytes: Separation, Collection and Transfusion, ed J M Goldman and R M Lowenthal, pp 499-509. London, Academic Press, 1975.

${ }^{6}$ Hill, R S, et al, Cryobiology, 1973, 10, 1.

7 Lowenthal, R M, et al, British fournal of Haematology, 1976, 34, 105.

${ }^{8}$ Pike, B L, and Robinson, W A, Fournal of Cellular and Comparative Physiology, 1970, 76, 77.

9 Böyum, A, Scandinavian fournal of Clinical and Laboratory Investigation, 1968, 21, suppl No 97, p 31.

${ }^{10}$ Storring, R A, et al, Lancet, 1977, 2, 837

${ }^{11}$ Enno, A, et al, Lancet, 1978, 2, 395.

12 Spiers, A S D, et al, British Medical fournal, 1975, 1, 175.

13 Vicariot, M, et al, European fournal of Cancer. In press.

${ }^{14}$ Catovsky, D, et al, Bollettino dell'Istituto Sieroterapico Milunese, 1978, 57, 344.

15 Goldman, J M, Catovsky, D, and Galton, D A G, Lancet, 1978, 1, 437.

16 Goldman, J M, Seminars in Hematology, 1978, 15, 420.

17 Goldman, J M, and Th'ng, K H, Cryoconservation des Cellules Normales et Neoplasiques, ed R S Weiner, R K Oldham, and L Schwarzenberg, p 71. Paris, Institut National de la Sante et de la Recherche Médicale, 1973.

18 Nothdurft, W, et al, Scandinavian fournal of Haematology, 1977, 19, 470.

19 Storb, R, et al, Blood, 1977, 50, 537.

20 Storb, R, Prentice, R, and Thomas, E D, New England fournal of Medicine, 1977, 297, 58.

${ }^{21}$ Janossy, G, Roberts, M, and Greaves, M F, Lancet, 1976, 2, 1058

${ }^{22}$ Buckner, C D, et al, Experimental Hematology, 1978, 6, 96.

\title{
Biochemical testing for acute medical emergencies in four district general hospitals
}

\author{
B T WILLIAMS, R A DIXON
}

British Medical fournal, 1979, 1, 1313-1315

\section{Introduction}

The growth in the number of requests for clinical biochemistry tests has been disproportionately greater than the growth in the numbers of patients treated in hospitals. ${ }^{1}$ Automation of some tests and a change in the clinicians' approach to testing from being selective in their ordering to requesting complete biochemical profiles of their patients are generally accepted to have contributed to this increase. ${ }^{2}$ The work loads of radiodiagnostic and physiotherapy departments have not increased so appreciably. ${ }^{3}$ The necessity for so much biochemical investigation has been challenged, ${ }^{4}$ and the need to evaluate its effectiveness in improving clinical treatment and outcome suggested. ${ }^{5}$ Some idea is first needed, however, of the range of biochemical tests being carried out by laboratories in specific clinical cases, such as we report here for acute medical emergencies.

\section{Patients and methods}

We selected four district general hospitals in four large urban areas of the Trent region, each of which had a busy accident and emergency department and provided a wide range of clinical services. Hospitals A and B were teaching hospitals, hospital B having only recently been designated and being without clinical teaching at undergraduate level. In each hospital a consultant chemical pathologist headed the clinical biochemistry department. The degree to which testing was automated varied. In hospital A 10 types of test were performed by one machine during normal working hours; at other times a smaller, six-test machine was used. The machine at hospital B provided only two simultaneous estimations. Hospital $\mathrm{C}$ used a four-test and a

Department of Community Medicine, University of Sheffield Medical School, Sheffield S10 2RX

R A DIXON, BSC, PHD, senior lecturer in medical statistics 
two-test machine concurrently, while hospital D used five single-test machines simultaneously.

To limit the scope for variation we restricted the study to patients aged 15-64 years gaining emergency admission-that is, being admitted on the day on which admission was arranged-to general medical beds during the first three months of 1976. A list of these patients was obtained from the Hospital Activity Analysis, which also provided the duration of stay and outcome in each case. Patients who had been investigated as inpatients or outpatients in general medicine in the previous year were excluded. Of the remainder, 200 were randomly selected so that the proportion under each consultant reflected his proportion of the specialty's emergency case load over the whole year. For each patient we obtained the presenting clinical problems from the case notes, which we also found to be the most complete source of the results of biochemical tests, even though laboratories nearly always had a record of a test having been performed. The proportion of tests performed for which results were found in the case notes ranged from $92 \%$ to $100 \%$ among the four hospitals.

The unit of information imparted by a laboratory was taken to be a "value." This may have been a quantitative test result (most commonly), a figure calculated from one or more test results such as the IgG to albumin ratio, or a qualitative observation.

\section{Results}

The four samples of patients each included more men than women and, except for hospital B, more patients aged 45-64 than 15-44 years. At each hospital the most common clinical presentation accounted for roughly half the cases (chest symptoms or signs at hospitals $\mathrm{A}$, $\mathrm{C}$; and $\mathrm{D}$; drug overdose at hospital $\mathrm{B}$ ). The median duration of stay was eight days in hospital A, three in hospital B, and four in hospitals $C$ and D. Death was the outcome in 18 cases in hospital A, 10 in hospitals B and C, and 22 in hospital D. The opportunity to investigate patients as inpatients was curtailed (by death, selfdischarge, or transfer to another hospital) in 30 cases in each of hospitals $A, B$, and $C$ and 46 in hospital D.

In all, 12635 test values were recorded for the 800 patients, giving an overall mean of 15.8 values per patient (table I). Of these values, $12196(97 \%)$ were derived from blood samples, $284(2 \%)$ from urine, and the remainder from cerebrospinal fluid, faeces, or pleural aspirate. Primary-that is, non-repeat-values accounted for $6960(55 \%)$ of the total. For each hospital a high (or low) mean number of primary values per patient was associated with a high (or low) mean number of repeat values. Moreover, hospital $A$, which had twice the mean number of primary values of either hospital B or C, had three times as many repeat values per patient as hospital $B$ and five times as many as hospital C. Yet hospitals B and C, not A, had the lowest death rates.

The median duration of stay was considerably higher in hospital A than in the other hospitals. Hospital A had the highest ratio of repeat to primary testing as well as the highest number of primary values, and it is tempting to infer that the plethora of primary values imparted by the laboratory, mainly during the first few days after admission, resulted in a more prolonged clinical appraisal and, therefore, length of stay.

The mean numbers of primary or repeat values per patient for individual consultants tended more closely to resemble those of their consultant colleagues in the same hospital than those of consultants in other hospitals. This suggests either that consultants working in the same hospital develop similar patterns of investigation or, perhaps more likely, that the policy of the laboratory, or the range of facilities it offers, determines the amount of data given to the clinicians on the ward. For each type of clinical presentation the differences in mean total values per patient between hospitals were broadly similar in magnitude and direction to the differences overall (table II). Although median durations of stay in hospitals $\mathrm{B}, \mathrm{C}$, and D were similar for comparable clinical presentations, appreciable differences occurred in the mean numbers of values for each of these clinical groups.

Altogether, the four laboratories reported 188 different types of value. A repertoire of 74 types was reported in hospital $A, 81$ in hospital B, 82 in hospital C, and 72 in hospital D. Despite the similar mix of cases at each hospital, only 30 types of value $(16 \%)$ were transmitted by all four laboratories. Even in comparable clinical circumstances considerable variations occurred among the hospitals in the types of primary test values reported (table III). In patients with chest symptoms urea and electrolyte concentrations were the values most frequently imparted. In hospital $D$, which had the highest number of primary values for urea and electrolytes per patient, these values comprised urea, sodium, potassium, chloride, and bicarbonate concentrations and the ions difference value, the latter being used only at this hospital. Hospital B did not report chloride concentrations at all, and hospital $\mathrm{C}$ only rarely. Three times as many cardiac enzyme values per patient were imparted for patients with chest disease in hospitals $\mathrm{A}$ and $\mathrm{B}$ as in hospital D, even though at each hospital over $70 \%$ of these patients had reported chest pain. In hospital D the only enzyme activity reported was that of creatine phosphokinase (CPK). Hospital A, as well as giving activity of CPK, gave that of two transaminases and lactate dehydrogenase. Hospital B reported values for one transaminase and the dehydrogenase, while hospital $\mathrm{C}$ reported values for CPK and the dehydrogenase.

The use of blood glucose estimations in the hospitals was comparable, but four times as many liver function test (LFT) values were given on average for the primary investigation of patients with chest symptoms in hospital A as in any other hospital. The LFT battery used routinely in hospital A consisted of six tests (three of enzymes) with alkaline phosphatase being estimated separately, and there were also six tests in the battery used in hospital C (one enzyme). The battery at hospital D consisted of eight tests (three enzymes). This indicates that LFTs were performed in a much higher proportion of cases presenting with chest problems in hospital $\mathrm{A}$ than in hospitals $\mathrm{C}$ and D, if not hospital B (where there were only four tests in the LFT battery).

TABLE I-Mean numbers of primary and repeat tests carried out per patient at each hospital, and ranges of numbers imparted to consultants (200 patients studied at each hospital)

\begin{tabular}{|c|c|c|c|c|c|c|c|}
\hline \multirow{2}{*}{ Hospital } & \multirow{2}{*}{$\begin{array}{l}\text { Median duration } \\
\text { of stay (days) }\end{array}$} & \multicolumn{2}{|c|}{ Primary tests } & \multicolumn{2}{|c|}{ Repeat tests } & \multicolumn{2}{|c|}{ Total } \\
\hline & & Hospital mean & $\begin{array}{c}\text { Range of } \\
\text { consultant means }\end{array}$ & Hospital mean & $\begin{array}{c}\text { Range of } \\
\text { consultant means }\end{array}$ & Hospital mean & $\begin{array}{c}\text { Range of } \\
\text { consultant means }\end{array}$ \\
\hline $\begin{array}{l}\text { A } \\
\text { B } \\
\text { C } \\
\text { D }\end{array}$ & $\begin{array}{l}8 \\
3 \\
4 \\
4\end{array}$ & $\begin{array}{r}12 \cdot 8 \\
6 \cdot 1 \\
6 \cdot 4 \\
9 \cdot 5\end{array}$ & $\begin{array}{r}10 \cdot 9-14 \cdot 6 \\
5 \cdot 0-7 \cdot 4 \\
5 \cdot 9-7 \cdot 7 \\
8 \cdot 1-12 \cdot 2\end{array}$ & $\begin{array}{r}14 \cdot 7 \\
4 \cdot 7 \\
2 \cdot 8 \\
6 \cdot 1\end{array}$ & $\begin{array}{l}7 \cdot 7-25 \cdot 8 \\
3 \cdot 7-5 \cdot 9 \\
2 \cdot 7-3 \cdot 1 \\
4 \cdot 4-7 \cdot 8\end{array}$ & $\begin{array}{r}27 \cdot 5 \\
10 \cdot 8 \\
9 \cdot 2 \\
15 \cdot 6\end{array}$ & $\begin{array}{r}18 \cdot 6-40 \cdot 4 \\
8 \cdot 7-12 \cdot 6 \\
8 \cdot 7-10 \cdot 8 \\
12 \cdot 8-20 \cdot 0\end{array}$ \\
\hline All hospitals & 5 & $8 \cdot 7$ & $5 \cdot 0-14 \cdot 6$ & $7 \cdot 1$ & $2 \cdot 7-25 \cdot 8$ & $15 \cdot 8$ & $8 \cdot 7-40 \cdot 4$ \\
\hline
\end{tabular}

TABLE II-Mean numbers of test values per patient according to clinical presentation (numbers of patients in parentheses)

\begin{tabular}{|c|c|c|c|c|c|c|c|}
\hline \multirow[b]{2}{*}{ Hospital } & \multicolumn{7}{|c|}{ Clinical presentation } \\
\hline & $\begin{array}{c}\text { Chest symptoms } \\
\text { and signs }\end{array}$ & $\begin{array}{c}\text { Alimentary } \\
\text { symptoms and signs }\end{array}$ & $\begin{array}{l}\text { Central nervous } \\
\text { system symptoms } \\
\text { and signs }\end{array}$ & Patient unconsciuus & Known overdose & Other & All presentations \\
\hline $\begin{array}{l}\mathbf{A} \\
\mathbf{B} \\
\mathbf{C} \\
\mathrm{D}\end{array}$ & $\begin{array}{c}29 \cdot 2(115) \\
16.6(63) \\
9 \cdot 9(85) \\
17.5(101)\end{array}$ & $\begin{array}{l}35.2(19) \\
13.5(20) \\
21.2(20) \\
20.2(18)\end{array}$ & $\begin{array}{r}32.4(25) \\
12.0(27) \\
8.7(21) \\
16.6(25)\end{array}$ & $\begin{array}{c}22.9(11) \\
16.8(4) \\
5.3(12) \\
14.1(12)\end{array}$ & $\begin{array}{l}5 \cdot 3(19) \\
3 \cdot 4(79) \\
3 \cdot 1(48) \\
8 \cdot 0(41)\end{array}$ & $\begin{array}{l}27 \cdot 6(11) \\
28 \cdot 3(7) \\
12 \cdot 7(14) \\
29 \cdot 7(3)\end{array}$ & $\begin{array}{r}27.5(200) \\
10 \cdot 8(200) \\
9 \cdot 2(200) \\
15.6(200)\end{array}$ \\
\hline
\end{tabular}


TABLE III-Mean numbers of primary values obtained for each group of tests used for two most common clinical presentations

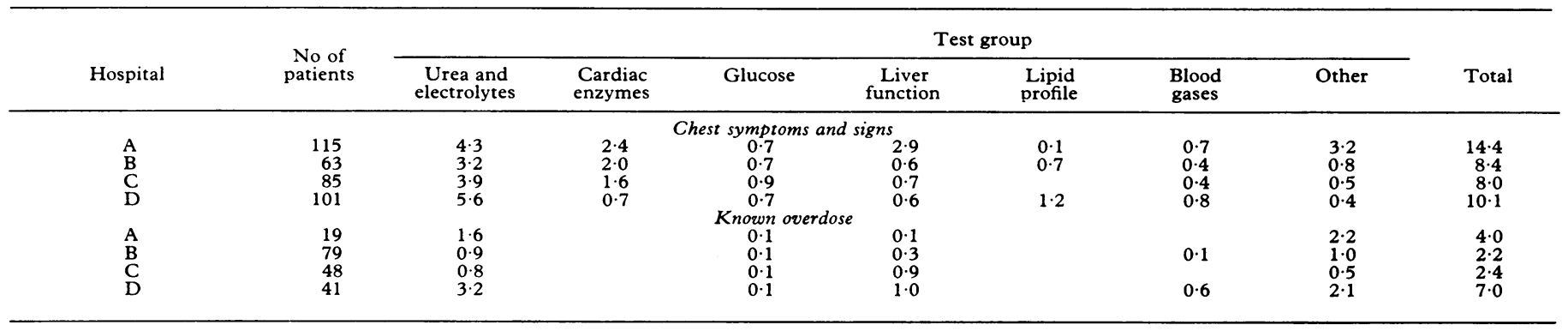

Each hospital reported three values in the lipid profile battery. Two values (serum cholesterol and triglyceride concentrations) were included in each hospital's profile. Three hospitals reported the serum appearance, while the fourth reported Frederickson's classification. For patients with chest symptoms hospital D made considerably more use of these tests than the other hospitals, and they were not used at all for patients with chest symptoms in hospital C.

There was a twofold difference among the hospitals in the mean number of primary blood gas values imparted per patient with chest symptoms. Other tests-measurement of serum creatinine concentrations in particular-were used most frequently in hospital A. In cases of known drug overdosage wide differences in the average numbers of electrolyte and LFT values existed between hospitals. The high level of reporting other test values in hospital D was largely due to measurements of the serum salicylate and barbiturate concentrations, while that in hospital A did not reflect a resort to any particular test.

\section{Discussion}

In this survey we found that extremely dissimilar types and amounts of biochemical test data were imparted in different hospitals for groups of patients with comparable clinical presentations. Since the rate of growth of acute services is being curtailed by economic circumstances, it would have been encouraging if a high volume of initial testing had permitted more rapid clinical appraisal and hence earlier discharge. Hospitals with high volumes of primary testing, however, also had high volumes of repeat testing and, if anything, tended to keep patients longer. What the higher level of investigation achieved is difficult to say. It did not reduce the likelihood of death. It may, however, have found the occasional result that was outside normal limits, leading to further investigation. The multiplicity of results may also have clouded the main issue for the investigating doctor, causing him to order additional clarifying . tests. The onus, therefore, is on high-volume laboratories like that in hospital A to justify so much investigation.

Exactly how much of the information supplied by these laboratories was superfluous for diagnostic precision and control of treatment is not known, nor is to what extent these functions suffered from lack of data and whether the general physicians were satisfied with the information they received. As well as variations in the amounts of data, there were appreciable qualitative differences, but whether these reflected the choices of the ordering physicians or the heads of the laboratories is uncertain. Enzyme studies are usually invoked to investigate possible organ damage, as in myocardial infarction, but the range of enzyme types varied between hospitals. Even before this study doubts existed about whether the routine measurement of enzyme activity in myocardial infarction affects decisions on diagnosis or treatment. ${ }^{6}$ Blood lipid concentrations are more often used to investigate cardiovascular disease in some hospitals than in others. The value of liver function tests, electrolyte studies, and estimations of serum drug concentrations in cases of drug overdosage also appears to merit further examination.

In teaching hospitals overinvestigation may be necessary to teach effectively. In this study the repertoire of tests used in the teaching hospital that had clinical students was in fact no broader than that in the other hospitals. This hospital simply used the same tests more frequently, reflecting perhaps a tendency to confirm for students the exclusion of diagnoses that could be excluded clinically and to show them the biochemical effects of treatment.

What then can be done to rationalise the use of laboratory investigation? Laboratories already co-operate to monitor the accuracy and precision of testing procedures through the national quality control scheme. Both clinical biochemists and ordering physicians may be receptive, therefore, to circulated advice on the value of individual tests in specific clinical circumstances, such advice necessarily arising from the pooled experience of acknowledged experts until evaluative trials become a routine source of information. As a method of promoting good and efficient practice in the fields of clinical and resource management precedents for this exist in the Notes on Good Practices circulated by the DHSS to health authorities; in Prescribers' fournal, an independent journal that carries expert opinion on matters related to drug prescribing; and in the cost comparisons of different pharmaceutical products having similar pharmacological actions, which are circulated by the DHSS to individual practitioners. (While such an advisory service might serve to promote more judicious selection of the type of test indicated or even to show how more discriminating use might be made of information already collected, ${ }^{7-9}$ clinicians do not always respond to advice on overutilisation even when they have agreed on the criteria for using certain tests. ${ }^{10}$ ) In formulating these criteria test information must be appraised according to its effect on clinical outcome. ${ }^{5}$

It follows that testing equipment should be built to specifications and used in ways that reflect the clinical usefulness of the data it produces.

We are grateful to the consultant pathologists who gave their advice, and to them and the general physicians concerned for permission to examine their records; to Mrs Jane Allen and Mrs Maureen Lockett for field work; and to the Trent Regional Health Authority for the research grant that financed the project. The views expressed do not necessarily reflect those of the Trent Regional Health Authority.

\section{References}

${ }^{1}$ Department of Health and Social Security, Health and Personal Social Services Statistics for England. London, HMSO, 1974-7.

2 Rose, H, and Abel-Smith, B, Doctors, Patients and Pathology. London, Bell, 1972.

${ }^{3}$ Vickers, H E, Lancet, 1966, 2, 46.

${ }^{4}$ Ashley, J S A, Pasker, P, and Beresford, J C, Lancet, 1972, 1, 890.

5 Holland, W W, and Whitehead, T P, Lancet, 1974, 2, 391.

${ }^{6}$ Boyle, C M, and Kapila, A, Lancet, 1973, 1, 538.

7 Buttner, J, fournal of Clinical Chemistry and Clinical Biochemistry, 1977, 15,1 .

${ }^{8}$ Kelly, A, et al, Clinical Chemistry, 1976, 22, 1723.

${ }^{9}$ Barnett, D B, et al, British Medical fournal, 1973, 2, 144.

${ }^{10}$ Eisenberg, J M, et al, Medical Care, 1977, 15, 915.

(Accepted 13 March 1979) 